UDC 13:140.8

Armenuhi MANUKYAN,

Mnatsakan MANUKYAN

\title{
PHILOSOPHICAL WISDOM AS A METHOD OF FORMATION OF WORLDVIEW OF AN INDIVIDUAL
}

\author{
Only those youngsters who are smart become wise at an old age.
}

Georg Brutian

\begin{abstract}
The article observes the role and significance of philosophical wisdom in the formation of person's worldview. It is also demonstrates the efficient ways of its usage, methods and conditions. It is noted that throughout ages Philosophy has mainly been studying the imagination, logic and abstract thinking of humans where the formation of personality is determined in its subjective existence. It is not secret that each phase of the development of civilization dictates new approaches and ideas, opinions and beliefs, values and standards, in other words, a new philosophy of life and being. Such transformations lead to the change of human being, to the modernization of his image and to the adaptation of a person to current demands. However, as a result of research and comparative analysis, we have come to the conclusion that, in spite of change in the mode of life and activities of a person, the main components characterizing the essence of a person remain unchanged. Among these components, the special role and importance is given to person's worldview as it decides his/her thinking and attitude towards the world and to himself/herslef, also to the quality of life style, morals and social aspects for which the effective way of formation is philosophical wisdom.
\end{abstract}

Keywords: philosophical wisdom, worldview, mean, formation, personality, human being, type, levels, concepts.

For centuries, human logic, imagination and abstract thinking have been the important aspects of the study of philosophy where the formation of a person depends on his uniqueness. It is not a secret that each phase of the development of civilization dictates new approaches and ideas, opinions and beliefs, values and standards, in other words, a new philosophy of life and being. These changes, in turn, contribute to the transformation of hu- man nature and the creation of a new image. However, in spite of a change in the mode of life and activities of a person, the main components characterizing the essence of a person remain unchanged. Among them, philosophical wisdom plays a special role, which is not only a powerful factor in preserving the national identity of the person, but also a way of shaping his worldview.

In the broadest sense of the word, philo- 
sophical wisdom is the environment of human's cognitive activity, his spiritual nature which is created, reproduced and transmitted to generations as formed stable values, traditions and wisdom. Philosophical wisdom as a result of human activity, is an alteration of nature in accordance with semantic laws and regularities. In this regard, it is noteworthy to quote M. Heidegger. He believes that human activity is organized in a meaningful way, which in modern world is regarded as implementation of supreme values by the perfect expression of human creativity.

By considering the philosophical wisdom as a way of shaping the worldview, we cannot miss out the theory of evolution, which in cultural studies and cultural anthropology is perceived as a process of adaption of human beings to their natural environment. Evolutionists in their approaches of philosophical wisdom highlight concepts which in terms of scientific laws, morals and laws of life should constitute as explanatory objects. In this regard, White's role is very valuable. He is a successor of philosophical wisdom studies which is an important part of the culture. For White's conception it is typical to aspire to define the objectives of philosophical wisdom which have its own patterns of functional development (White, 1959, p. 29).

They are very diverse but among that diversity the most important is the formation of person's worldview in the implementation of which, in certain chronological sequence, ideas accumulated over the centuries have transformed into wisdom. It is not a secret that a person's worldview is shaped not only by the assumption of knowledge but mostly by certain cultural traditions and wisdom due to peculiarities of family education. The formation of philosophical wisdom is an independent process where in the result of interaction of cultural attributes occur clear convictions. Thanks to those convictions a person is regarded as a developing system and semantic factor of evolution. The initial element of wisdom is the person's ability to understand symbols, loans and allegories, also the perception of their physical form and meaning. Unfortunately, not everyone has that ability. Nowadays, there are many smart but few wise people.

Let's try to understand what wisdom is. In Ozhogov's dictionary it is defined as the unity of intelligence, knowledge and experience. But this definition does not include the idea of love. Due to our strong belief there cannot be wisdom without love. Only the idea expressed with love can be wise. To be wise means to live with love and in love by displaying and disseminating the light which is peculiar to wise mind full of love. Thanks to that many "Wisdom Schools" have been formed, preserved and reached to us over the centuries and by their powerful influence many generations have formed their outlooks and beliefs about the surrounding world.

The term "worldview" was introduced into scientific circulation in the second half of XVIII century. The term comes from German "Weltanschauung" word and refers to a wide world perception. Of course, it is obvious that notions about worldview existed before the origin of this term in ancient world and was described as wisdom or high knowledge The issues related to the formation of worldview are rooted in the unity and integrity of the world surrounding man and balancing the concept about life and death is a cognitive need for every individual. In the modern 
world the worldview is perceived as a point of view of a person about his role in life and society. The point of view includes attitudes, beliefs, principles and morals. In other words, worldview is a complete way to understand the self and to generalize views about the surrounding world and man's place and role in it. Taking this into account, we can argue that through philosophical wisdom it is possible to achieve self-awareness and to the identification of man's role and place in the world as each of them involves components, levels and forms about worldview.

A.A. Radugin classifies four structural components of the worldview of an individual. They are cognitive component, valueorientation component, emotional-volitional component and practical component.

The cognitive component includes knowledge which man acquire from different sources and in different ways during his lifetime. The philosophical wisdom can be one of those ways and sources. Therefore, cognitive component provides the scientific side of the world which encompasses personal and social skills in generalized and systematic manner.

Value-oriented component is based on different values, beliefs and ideals. It includes social norms and moral interpretations of phenomena, the understanding of which leads to a proper formation of interpersonal and social relations. Obviously, philosophical wisdom, which is generated from universal values, is equipped with this component. The system of values imply the meaning of life, happiness, misfortune, notions of good and evil, love and hate, attitudes and beliefs.

Emotional-volitional component is the emotional side of values, beliefs and convictions and provides psychological functioning of those elements. They are formed more effective under the influence of philosophical wisdom.

Practical component involves practical application of theoretical knowledge. In other words under the influence of philosophical wisdom human lifestyle is formed according to certain values, beliefs, orientations, principles and attitudes.

It is natural that the worldview of every man comprises the above mentioned components but each of them appear in a favorable situation depending on individual's age, personal qualities, practice and wisdom. Therefore, in the framework of worldview the individual's cognitive and emotional experience, his emotionality and intelligence are performed in different ways which is considered as the basis of emotional-psychological worldview and is called "world perception". The individual's perception about the world, its effectiveness and goal-orientation is greatly influenced by philosophical wisdom, which, in this case, is a powerful method of influence.

It should be noted that both in native and foreign schools of philosophy, the worldview is traditionally classified into household, theoretical and practical types. Nevertheless, they are logical continuation of each other and in the scope of "world perception" are linked to each other. Certainly, there are some differences which depend on individual's good knowledge, ideas and reasoning, critical and logical thinking, imagination and wisdom. We strongly believe that philosophical wisdom as a method of formation of worldview, can also contribute to a formation of the personality, can strengthen priorities both in household practical and theoretical levels. For instance, 
in level of household worldview, man expresses his daily routine values, the interpretation of which vary in the framework of philosophical wisdom, folk traditions, customs and social stereotypes. Yet, the theoretical level of the worldview is the superstructure of daily practical level, which stands out by its systematization and hierarchical structure.

After analyzing the influence of philosophical wisdom on the formation of individual's worldview, we have come to the following conclusions:

- Philosophical wisdom is a universal, cultural and natural value through which personal, historical and social experiences are transferred from generation to generation.

- Philosophical wisdom has educative, formative and developing function.

- Philosophical wisdom as a way to formation of an individual's worldview is perceived in the framework of evolutionary and cognitive theories.

- Philosophical wisdom in the framework of culture and cultural anthropology is perceived as a process of adaptation of an individual to natural environment.
- Philosophical wisdom acts as explanatory objects in accordance with scientific approvals, morals and rules of life.

- Through philosophical wisdom is formed not only the person's worldview but also his world perception.

- Philosophical wisdom can have personal, pedagogical and psychological interpretations.

\section{REFERENCES}

Brutian, G.A. (2010). Gitakan ashxatanqi texnologia (Technology of Research Work, in Armenian), Pilisopayut'yan mijazgayin akademiayi hratarakchut'yun, Yerevan.

Heidegger, M. (1986). Time of the Worldview/ The new technocratic war in the west. M.

Radugin, A.A. (2004). Filosofiya: kurs lektsii (Philosophy: Course of Lectures, in Russian), Moscow, Tsentr.

White, L. (1959). The Evolution of Culture, New York. 